\title{
Struggle to survive: aphid-plant relationships under low-light stress. A case of Acyrthosiphon pisum (Harris) and Pisum sativum L.
}

\author{
Katarzyna Dancewicz ${ }^{1}$ (D) Marlena Paprocka ${ }^{1} \cdot$ Iwona Morkunas $^{2} \cdot$ \\ Beata Gabryś ${ }^{1}$
}

Received: 11 January 2017 / Accepted: 24 July 2017/Published online: 1 August 2017

(C) The Author(s) 2017. This article is an open access publication

\begin{abstract}
Light is primary source of energy and also plays signaling and regulatory roles in developmental processes and defense responses of plants. The aim of the study was to determine the performance, settling preferences, probing, and feeding behavior of Acyrthosiphon pisum on Pisum sativum grown in complete darkness (NL), with light at minimum level required for photoperiodic reaction (LL) and under full-light (FL) conditions. The effect of $A$. pisum infestation on metabolic status and defense responses of peas under FL, LL, and NL conditions was also determined. The population growth rate was limited on LL and NL pea plants as compared to FL plants. The reproductive period of aphids on LL and NL plants was eight times shorter than on plants growing in FL. In contrast to aphids on FL plants, the majority of A. pisum rejected LL and NL plants during settling. Aphid probing activities were not impeded on LL and NL plants but the probes were significantly shorter than on FL plants and consisted mainly of non-phloem activities. The analysis of tolerance of $P$. sativum to A. pisum showed that on FL plants, the number of aphids was nearly five times higher than on plants growing in low light (LL) at the end of the 2-week experiment but the tolerance index of FL plants was higher than that of LL plants. The contents of chlorophyll a, chlorophyll b, carotenoids, saccharides, and phenolics and
\end{abstract}

Handling Editor: Robert Glinwood.

Beata Gabryś

b.gabrys@wnb.uz.zgora.pl

1 Department of Botany and Ecology, University of Zielona Góra, Prof. Z. Szafrana 1, 65-516 Zielona Góra, Poland

2 Department of Plant Physiology, Poznań University of Life Sciences, Wołyńska 35, 60-637 Poznań, Poland the activity of $\beta$-D-glucosidase were notably lower in LL and NL plants than in FL plants. The increase in light intensity from complete darkness to the minimum level required for photoperiodic reaction did not stimulate evident changes in the measured plant biochemical parameters. These trends occurred in aphid-free (AF) and aphidinfested (AI) plants. However, under FL conditions, $\beta$-Dglucosidase activity and the content of saccharides were lower in AI plants than in AF plants. No differences in the measured plant biochemical parameters between AI and AF plants occurred under LL and NL conditions. The low $\beta$-D-glucosidase activity and low content of phenolics in the light-deprived plants that have reduced ability to photosynthesize show that under the biotic stress of aphid infestation plants invest in supporting basic metabolism rather than in defense against herbivores.

Keywords Aphid demographic parameters - Aphid feeding behavior - Low-light stress - EPG technique . $\beta$-D-glucosidase

\section{Introduction}

Pea (Pisum sativum L.) (Fabaceae), originally a plant of the Near East and one of the most ancient crops dating back to the end of the last Ice Age in Europe, is currently grown all over the world in temperate regions, at low and high elevations or during cool seasons in warm regions (Ljuština and Mikić 2010; Pavek 2012). Pea is cultivated basically in pure stands as a commercial crop but it is also used as a forage, rotational, and cover crop or green manure. Peas are also included in the intercropping systems to accompany cereals and other legumes or in orchards (Akemo et al. 2000; Zorić et al. 2012; Chapagain and Riseman 
2014). As the companion crops, legumes in general and peas in particular are intended to improve soil fertility through their ability of nitrogen fixation and/or decrease the probability of pathogen, pest or weed infestation in the main crop (Huňady and Hochman 2014; Cupina 2016).

The intensity of light is one of the crucial environmental factors that determine the life of autotrophic plants, including basic life processes such as the level of photosynthesis and photoperiodic reactions. Apart from being the primary source of energy, light also plays signaling and regulatory roles in developmental processes thanks to photoreceptors that receive and transmit light signals (Gyula et al. 2003; Chory 2010; Eckstein et al. 2012). The developmental changes that occur in response to light exposure are associated with the regulation of multiple plant hormones at the level of synthesis, transport, or signaling (Weller et al. 2015). Therefore, the impact of light on the plant growth is a complex phenomenon. Plant reaction to light depends on genotype and life cycle of plants. In the course of evolution, the competition for light forced the ecological specialization among plant species, which led to the emergence of a wide spectrum of plant taxa with varying photo-requirements, from heliophytes (=shade-avoiding plants) to sciophytes (=shade-adapted plants). Heliophytes differ from sciophytes in a number of morphological and physiological traits (Givnish 1988; Lambers et al. 2008). Due to acclimation, differences in physical and physiological characteristics occur also between shade- and sun-growing leaves within one plant individual (Lichtenthaler et al. 1981; Terashima et al. 2006). At the same time, all plants have evolved diverse mechanisms to counteract the rapid and irregular changes in light intensity during the day to optimize the light energy absorption and use. These mechanisms are long-term or short-term and may involve whole plants as well as cellular and molecular levels, including the leaf area and plant height, leaf orientation, position of chloroplasts in the cell, chlorophyll content, and photosystem modulation (Ruban 2009, 2015). Nevertheless, the prolonged and continuous deficit of light may have profound direct and indirect consequences for the physiology, development, and survival of plants that are naturally not adapted for life in the shade. The direct aftermath of long-lasting low irradiation conditions is the disintegration of photosynthetic apparatus, which causes insufficient ATP production for carbon fixation and carbohydrate biosynthesis (Shao et al. 2014; Maguire and Kobe 2015). The shortage of simple sugars, the original basic substrates for all biosynthetic pathways, affects every aspect of primary and secondary metabolism of the plant cell. The indirect effects of inadequate irradiation on plant secondary metabolism appear particularly important in the ecological context, especially when considering plant relationships with other organisms. The level of carbohydrates as the end product of photosynthesis is extremely important in the mobilization of defense mechanisms of plants against biotic stressors (Morkunas et al. 2005; Morkunas and Bednarski 2008, 2011, 2016). Secondary plant chemicals act as elements of intra- and inter specific communication and offense-defense systems within food webs associated with a particular plant species (Karban and Agrawal 2002; Norin 2007; Kliebenstein 2012; War et al. 2012; Formela et al. 2014). The defensive role of secondary metabolites may involve a deterrent or an antifeedant activity, toxicity, or participation as precursors in physical defense (Bennett and Walsgrove 1994).

In nature, P. sativum prefers well lit places (Hill 1999; Zarzycki et al. 2002). When grown together with cereals or in orchards, peas may suffer from the deficit of light due to shading. Indeed, low irradiance levels have negative impact on various aspects of physiology and development of peas. The pea seedlings grown under low irradiance stress develop fewer internodes, exhibit suppressed leaf expansion, and alter the gibberellin levels (Gawronska et al. 1995). Stem elongation in pea seedlings varies with light conditions (Elliott and Miller 1974). Sorce et al. (2008) showed that auxins are involved in stem elongation, the process that depends on light intensity and spectral characteristics. Low-light intensity makes the photosynthetic apparatus of peas more susceptible to lead toxicity (Romanowska et al. 2006). The rate of photosynthesis in $P$. sativum decreases as the light level decreases (Akhter et al. 2009). Finally, the lower rate of photosynthesis may cause a decrease in the intensity of nitrogen fixation (Garg and Singla 2004; Kirizii et al. 2007).

Among a variety of herbivores that feed on legumes, the pea aphid Acyrthosiphon pisum (Harris) (Hemiptera: Aphididae) is of special importance. It is a well-known worldwide oligophagous species that infests leguminous plants and transmits over 30 virus diseases (Blackman and Eastop 1985). Like all aphids, A. pisum feeds upon phloem sap and penetrates plant tissues using its piercing-sucking mouthparts to reach sieve elements. The route of aphid stylets is basically intercellular with brief 5-7 s punctures into cells adjacent to stylet tracks for gustatory purposes (Pettersson et al. 2007). The punctured cells regain their integrity immediately after stylet penetration (Tjallingii and Hogen Esch 1993). Nevertheless, despite the fact that the damage to plant cells during feeding is minimal, aphid infestation causes significant changes in plant physiology, such as a loss of chlorophyll a and chlorophyll b (Goławska et al. 2010). Chlorosis due to chlorophyll degradation is a typical injury symptom elicited by aphid feeding (Wang et al. 2004; Heng-Moss et al. 2003; Quisenberry and Ni 2007). The susceptibility of leguminous plants to the pea aphid infestation depends partly on the amount of phenolics in plant tissues, especially in the 
species lacking other lines of constitutive chemical defense, which is the case in $P$. sativum (Goławska and Łukasik 2012). In other plant species, such as lupins or alfalfa, the relative content of alkaloids in lupins and the occurrence of saponins in alfalfa determine the susceptibility of different varieties of these plants to the pea aphid (Goławska and Łukasik 2009; Kordan et al. 2012).

In nature, plants and animals are exposed to environmental change. However, the crosstalk between biotic and abiotic stresses in aphid-plant systems has been examined extremely rarely. Khan et al. $(2010,2011)$ investigated the performance of Brevicoryne brassicae (L.) and Myzus persicae (Sulz.) and glucosinolate profile in water-stressed Brassica oleracea L. Mewis et al. (2012) analyzed the effect of aphid feeding and water stress on the metabolite composition in Arabidopsis thaliana (L.). The present study is the first report on aphid performance, settling preferences, probing behavior and feeding activity as well as plant responses to aphid feeding under full-, low-, and no-light conditions. We provide information on how the extended periods of low irradiation or light deprivation affect plant suitability to aphids and how the pea aphid infestation affects the plant defense system, especially the accumulation of phenolic compounds, under the low-light stress. At the same time, we addressed the plant physiology issue to reveal whether the minimum light intensity that triggers photoperiodic reaction does also trigger plant responses to aphid infestation.

\section{Materials and methods}

\section{Aphids}

The stock culture of the pea aphid Acyrthosiphon pisum (Harris) was maintained as a multiclonal colony on Pisum sativum L. cv. Cysterski under laboratory conditions at $65 \%$ R.H., $20^{\circ} \mathrm{C}$, and long day photoperiod (L16:8D) in a growing chamber Sanyo MLR-352H. To maintain colony vitality, apterous aphids were transferred to non-infested plants every other week. Transfer of aphids to new plants consisted of excising an aphid-infested leaf and placing it atop of new plants to allow independent aphid movement to fresh plant leaves. For all experiments involving aphids, one to seven days old adult apterous females of $A$. pisum were collected from the stock culture. According to ten Broeke et al. (2013), the use of aphids of random ages gives a clear view of the behavior of adult aphids within a population.

\section{Plants}

Pisum sativum L. cv. Cysterski purchased from Poznańska Hodowla Roślin Sp. z.o.o. in Tulce near Poznań, Poland was used for all experiments. For germination and growing, plastic pots $(0.33$ 1) filled with fine garden soil commonly used for greenhouse experiments purchased from Hollas Sp. z.o.o. from Pasłęk, Poland were applied. Plants were watered regularly and no additional nutrients were supplied. The growing conditions were $65 \%$ R.H., $20{ }^{\circ} \mathrm{C}$, and long day photoperiod (L16:8D). Plants were kept in a growing chamber Sanyo MLR-352H. The light source was a bank of fluorescent tubes Mitsubishi/Osram FL 40 SSW/ 37 (fluency rate $91.99 \mu \mathrm{mol} \mathrm{s}{ }^{-1} \mathrm{~m}^{-2}$ ). At the time of sowing, plants $(n=210)$ were divided into three sets $(n=70)$ and grown for two weeks under three different light regimes: full light $(\mathrm{FL}$; fluency rate $91.99 \mu \mathrm{mol} \mathrm{s} \mathrm{m}^{-1}$ ), low light (LL; $0.01 \mu \mathrm{mol} \mathrm{s}{ }^{-1} \mathrm{~m}^{-2}$ ), and no light (NL; $0.0 \mu \mathrm{mol} \mathrm{s} \mathrm{s}^{-1} \mathrm{~m}^{-2}$ ). The fluency rate at $0.01 \mu \mathrm{mol} \mathrm{s}{ }^{-1} \mathrm{~m}^{-2}$ is the threshold value for the first positive phototropic reaction found in Arabidopsis thaliana (L.) Heynh and other plant species (Janoudi and Poff 1990). The LL and NL conditions were achieved by placing the plants in cabinets with partly or completely shaded walls, respectively. Light measurements were taken using LI-250A Light Meter with a LI-COR quantum sensor, serial number: Q34734 (Lincoln, Nebraska USA). After 2-weeks of exposure to the different light conditions, the following experiments were carried out: (i) evaluation of performance of aphid-free and aphid-infested plants under full-, low-, and no-light conditions (ii) evaluation of plant responses to aphid infestation under full-, low-, and no-light conditions, and (iii) evaluation of pea aphid performance, settling preferences, probing behavior, and feeding activity on plants grown under full-, low-, and nolight conditions.

\section{Evaluation of plant performance}

Performance of aphid-free and aphid-infested plants was evaluated by measuring plant tolerance to aphid infestation under full-, low-, and no-light conditions.

Two-week old plants (six true leaves in control plants) $[n=42]$ collected randomly from the initial culture under FL $[n=14]$, LL $[n=14]$ and NL [ $n=14]$ light regimes were divided into two sets. Plants of one set $[n=21]$ were placed under respective light conditions for further 2 weeks with no access of aphids (aphid-free plants: AFFL $[n=7]$, AF-LL [ $n=7]$, AF-NL [ $n=7]$, respectively). Each plant of the other set $[n=21]$ was infested with 10 adult apterae of $A$. pisum. Each plant was put separately in a plastic container and placed under respective light conditions for 2 weeks (aphid-infested plants: AI-FL [ $n=7]$, AI-LL [ $n=7]$, AI-NL [ $n=7]$, respectively). No aphids were removed during the experiment. After the 2-week experimental period, plants were removed from the pots, washed, dried, and weighed using RADWAG PS 600/C/2 
balance. Aphids were removed from each plant separately and their number was counted. As a measure of plant tolerance to aphid infestation, weight index of plants (WI), tolerance index (TI) of plants to pea aphid infestation, and relative weight change of plants (DWT) were calculated according to the formulae: $\mathrm{WI}=\left[\left(W_{\mathrm{AF}}-W_{\mathrm{AI}}\right) / \mathrm{AP}\right] \times$ $100, \quad \mathrm{TI}=\left\{\left[\left(W_{\mathrm{AF}}-W_{\mathrm{AI}}\right) / W_{\mathrm{AF}}\right] / \mathrm{AP}\right\} \times 100, \quad \mathrm{DWT}=$ $\left[\left(W_{\mathrm{AF}}-W_{\mathrm{AI}}\right) / W_{\mathrm{AF}}\right] \times 100$, where $W_{\mathrm{AF}}$ is weight of aphid-free (AF) plants, $W_{\mathrm{AI}}$ is weight of aphid-infested (AI) plants, AP is the number of pea aphids on the infested plant at the end of experiment (Reese and Schwenke 1994).

\section{Evaluation of plant responses to light deprivation and aphid infestation}

Plant responses to aphid infestation under different light intensities were evaluated by measuring the content of photosynthetic pigments (chlorophyll a, chlorophyll b, and carotenoids), sugars, $\beta$-D-glucosidase activity, and total phenolics in $P$. sativum leaves in aphid-free (AF) and aphidinfested (AI) plants grown at three light regimes.

Two-week old plants (six true leaves in control plants) $[n=42]$ collected randomly from the initial culture under FL $[n=14]$, LL $[n=14]$ and NL [ $n=14]$ light regimes were divided into two sets. Plants of one set were placed under respective light conditions for further 2 weeks and remained aphid-free (aphid-free plants: AF-FL $[n=7]$, AF-LL $[n=7]$, AF-NL [ $n=7]$, respectively). Each plant of the other set $[n=21]$ was infested with five adult apterae of $A$. pisum. Each plant was then put separately in a plastic container and placed under respective light conditions for two weeks (aphid-infested plants: AI-FL [ $n=7]$, AI-LL $[n=7]$, AI-NL $[n=7]$, respectively). No aphids were removed during the experiment. After two weeks of exposure to the different light conditions, the leaves of pea plants were removed from plants, weighed, frozen, and kept at $-21^{\circ} \mathrm{C}$ until the analysis. Aphids from the aphid-infested plants were removed prior to the preparation of plant samples.

\section{Determination of photosynthetic pigments contents}

Total chlorophyll and carotenoids were extracted by dimethylsulfoxide (DMSO) according to the method of Hiscox and Israelstam (1979). Samples (0.5 g) of pea leaves were placed in a glass tube containing $5 \mathrm{~cm}^{3}$ DMSO. Samples were incubated in a water bath at $65^{\circ} \mathrm{C}$ for $1 \mathrm{~h}$, in the dark. Absorbance was measured spectrophotometrically (Jasco V-530, Tokyo, Japan) at 480, 649, and $665 \mathrm{~nm}$, relative to a DMSO blank. Chlorophyll a and chlorophyll $b$ as well as total carotenoids contents were calculated following the equations proposed by Wellburn (1994).

\section{Determination of total saccharides content}

$0.5 \mathrm{~g}$ of plant material was homogenized in $1.5 \mathrm{ml}$ distilled water at $4{ }^{\circ} \mathrm{C}$. Homogenate was centrifuged at $15,000 \times g$ and $4{ }^{\circ} \mathrm{C}$ for $15 \mathrm{~min} .1 \mathrm{ml}$ of supernatant was added to $2 \mathrm{ml}$ of cooled 0.02 antronic reagent in sulphuric acid and heated at $90{ }^{\circ} \mathrm{C}$ for $14 \mathrm{~min}$ (Björnesjö 1955). Under the effect of sulphuric acid, saccharides transform into furfural derivatives which together with antron yield blue and green products. After incubation, the mixture was stirred and cooled. The absorbance was measured with a UV-spectrophotometer Jasco V-530, Tokyo, Japan at $620 \mathrm{~nm}$. The content of saccharides was calculated from a standard curve prepared for glucose. The final results, which were the means of four replications, were expressed in $\mathrm{mg}$ of glucose per $\mathrm{g}$ of fresh weight.

\section{Extraction and assay for $\beta$-D-glucosidase activity}

The activity of $\beta$-D-glucosidase (EC 3.2.1.21) was determined spectrophotometrically (Perkin Elmer Lambda 15 UV-Vis spectrophotometer, Norwalk, CT) on the basis of the method proposed by Nichols et al. (1980) and modified by Morkunas et al. (2007). Plant material $(500 \mathrm{mg}$ ) was ground at $4{ }^{\circ} \mathrm{C}$ in $0.05 \mathrm{M}$ phosphate buffer of $\mathrm{pH} 7.0$ and $1 \%$ polyvinylpyrrolidone (PVP). Supernatant obtained after centrifugation at $15.000 \times g$ for $20 \mathrm{~min}$ was used to determine the enzyme activity. The mixture containing $0.2 \mathrm{ml}$ phosphate buffer $(0.05 \mathrm{M}, \mathrm{pH} 7.0), 0.2 \mathrm{ml}$ extract, and $0.2 \mathrm{ml}$ 4-nitrophenyl-b-D-glucopyranoside as substrate $\left(2 \mathrm{mg} \mathrm{ml}^{-1}\right)$ was incubated for $1 \mathrm{~h}$ at $35^{\circ} \mathrm{C}$. After that time, $0.6 \mathrm{ml} 0.2 \mathrm{M} \mathrm{Na}_{2} \mathrm{CO}_{3}$ was added. The formation of $p$-nitrophenol ( $p$-NP) was followed at $400 \mathrm{~nm}$. The activity was measured in three replications and expressed as $\mu \mathrm{M} p$ nitrophenolx $\mathrm{g}^{-1} \mathrm{FW} \mathrm{h}^{-1}$.

\section{Determination of phenolic compounds contents}

The content of phenolic compounds in plant extract was determined spectrophotometrically (Perkin Elmer Lambda $15 \mathrm{UV}-\mathrm{Vis}$ spectrophotometer, Norwalk, CT) on the basis of the method proposed by Swain and Hillis (1959) with modifications. Plant material $(0.5 \mathrm{~g})$ was ground in $4 \mathrm{ml}$ $80 \%$ methanol and incubated for $10 \mathrm{~min}$. at $60{ }^{\circ} \mathrm{C}$. After incubation, $0.5 \mathrm{ml}$ of the diluted reaction solution, $3 \mathrm{ml}$ $\mathrm{H}_{2} \mathrm{O}$ and $0.1 \mathrm{ml} 1 \mathrm{~N}$ Folin-Ciocalteu reagent were pipetted and the mixture was allowed to react for $3 \mathrm{~min}$ under continuous stirring. Next, the reaction was interrupted by a solution of sodium carbonate $(1 \mathrm{ml} \mathrm{10 \% )}$. Absorbance was measured after $20 \mathrm{~min}$ at $660 \mathrm{~nm}$. The results were expressed as $\mu \mathrm{g}$ chlorogenic acid $\mathrm{g}^{-1} \mathrm{FW}$. 


\section{Aphid performance}

Aphid performance was evaluated on plants grown under three light regimes (FL, LL, NL) by studying basic demographic parameters: duration of pre-reproductive, reproductive, and post-reproductive periods and daily and total fecundity. Intrinsic rate of natural increase, net reproduction, and mean time of generation development were calculated as well.

One adult apterous aphid was collected from the stock culture and placed on the top leaf of the experimental plant that derived from the FL, LL, and NL sets of plants prepared as described previously (that is the plants kept in full, low, and no access to light for two weeks before; $n=16$ per each treatment). The aphid female was permitted to reproduce for $24 \mathrm{~h}$ and then the adult aphid and all but one nymph were eliminated from the leaf. The pre-reproductive period was established by daily checking of individual nymphs from time of birth to the final molt. Aphids were not confined in the clip cages. After maturity and the beginning of reproduction, adult mortality and fecundity were recorded and the offspring were removed daily until the death of the adult aphid. The intrinsic rate of natural increase $\left(r_{\mathrm{m}}\right)$ was calculated using the following equation: $r_{\mathrm{m}}=[0.74(\mathrm{lnMd})] / D$, where 0.74 is the constant for aphids and mites, Md is the number of nymphs produced in the first $D$ days of reproduction after the adult molt and $D$ is the development time of the aphid (i.e., from birth to the final molt but before the onset of reproduction) (Wyatt and White 1977; Awmack and Leather 2007). The net reproduction $\left(R_{0}\right)$ and mean length of a generation $(T)$ were calculated according to formulae: $R_{0}=\Sigma\left(l_{x} m_{x}\right)$ and $T=\Sigma$ $\left(x l_{x} m_{x}\right) / \Sigma\left(l_{x} m_{x}\right)$, where $l_{x}$ denotes the number of individuals alive at age $x, m_{x}$ is adult fecundity during age $x$, and $x$ is the age of female (Birch 1948; Soffan and Aldawood 2014). The demographic parameters of 16 aphids per each treatment were recorded (one aphid per plant). Plants with aphids were kept separately in transparent plastic containers under respective light regimes (FL, LL, and NL) for the duration of the experiment (i.e., until the death of the mother aphid).

\section{Aphid settling preferences}

The settling preference of aphids in a simple choice biological assay was monitored using the detached leaves of plants grown under three light regimes: FL, LL, and NL. A Petri dish was divided into two halves by drawing a line. Apical parts of the experimental plants were cut off and placed in a Petri dish, one in each half (FL:LL and FL:NL). The cut petioles were enveloped with watered cotton wool to provide moisture to the leaves. Adult apterous aphids (1-5 days old) were collected from the stock culture and placed in the dish along the line that divided the arena into two halves so that aphids could move freely and choose between the two leaves (FL vs. LL and FL vs. NL). Aphids that settled, i.e., they did not move and the position of their antennae indicated feeding (Hardie et al. 1992) on each leaf were counted at 1,2 , and $24 \mathrm{~h}$ intervals after access to the leaf. Aphids that were moving or out of any of the leaves were not counted. The experiment was conducted during the day and under moderate white light illumination at fluency rate of $30 \mu \mathrm{mol} \mathrm{s}{ }^{-1} \mathrm{~m}^{-2}$. The plants were offered to aphids immediately after having been removed from their growing chamber. In total, 8 replications with 20 viviparous apterous females per replicate per treatment were performed.

\section{Aphid probing behavior}

Aphid probing behavior was monitored using the Electrical Penetration Graph technique (DC-EPG system, Tjallingii 1985, 1988), which is commonly applied in studying Hemiptera-plant interactions. In this experimental set-up, aphid and plant are made parts of an electrical circuit, which is completed when the aphid inserts its stylets into the plant. Weak voltage is supplied to the plant, and all voltage changes are recorded as EPG waveforms that have been correlated with aphid activities and stylet tip positions in plant tissues (Tjallingii 1994; Pettersson et al. 2007; http://www.epgsystems.eu/epg/measuring-systems). The values of parameters derived from EPG recordings, e.g., the duration of probing, duration of phloem sap ingestion, number of probes, etc., reflect the level of suitability of plants to aphids (Mayoral et al. 1996; Pettersson et al. 2007; Philippi et al. 2015; http://www.epgsystems.eu/file/ 46-waveform-features). Adult (1-5 days old) apterous females of A. pisum were collected from the stock culture and their probing behavior was recorded on plants grown under three light regimes (FL, LL, NL) for $8 \mathrm{~h}$ continuously. After the attachment of the golden wire electrode (Manual-Giga-8d.pdf http://www.epgsystems.eu/down loads, section Manuals), aphids were starved for $1 \mathrm{~h}$ prior to the experiment. The recordings were started at 10-11 a.m. and continued during the day under moderate white light illumination at fluency rate of $30 \mu \mathrm{mol} \mathrm{s}{ }^{-1}$ $\mathrm{m}^{-2}$. The plants were offered to aphids immediately after having been removed from their growing chambers. Each plant-aphid set was considered as a replication and was tested only once. The number of replications for each treatment was 21. However, after the examination of the recordings, only the replications that included complete 8-h recording were kept for analysis, which were: $n=21$ for FL plants, $n=16$ for LL plants, and $n=14$ for NL plants. Giga-8 DC-EPG system with a $1 \mathrm{G} \Omega$ of input resistance (EPG Systems, Wageningen, The Netherlands) was used to 
record EPGs. EPGs were recorded and analyzed using Stylet + Software (EPG Systems, Wageningen, The Netherlands). The following EPG signals were distinguished: np (non-penetration-aphid stylets outside the plant), C (penetration of non-phloem tissues, e.g., pathway phase including intercellular apoplastic stylet pathway and intracellular stylet punctures 'pd'), G (active intake of xylem sap from xylem elements), $F$ (derailed stylet movements associated to stylet penetration difficulties), E1 (salivation into sieve elements), and E2 (ingestion of phloem sap). The E1/E2 transition patterns were included in E2. Xylem sap ingestion and derailed stylet movements occurred sporadically, therefore these events were combined with pathway activities in all calculations and defined as non-phloem activities. The cell-puncturing aphid activity during pathway was evaluated by counting standard cell punctures 'pd' and repetitive cell punctures 'r-pd'. Repetitive cell punctures ('r-pd' $=$ repetitive potential drop) are peculiar punctures associated with repeated probing in phloem tissue prior to the continuous contact with sieve elements. These special repetitive 'sieve element testing' punctures are characteristic of A. pisum among other species (Tjallingii and Gabrys 1999). A number of sequential (i.e., describing the sequence of events during the recording) and non-sequential (i.e., referring to frequency and total and average duration of patterns) parameters were calculated (van Helden and Tjallingii 1993) and analyzed in configuration related to activities in peripheral and vascular tissues. The waveform patterns that were terminated before the end of the experimental period $(8 \mathrm{~h})$ were not excluded from the calculations. In sequential parameters, when time to waveforms related to phloem phase (E1 or E2) was calculated, if no phloem phase occurred, the time from the 1st probe until the end of the recording was used. In non-sequential parameters, when a given waveform had not been recorded for an individual, the duration of that waveform was given the value of 0 .

\section{Statistical analysis}

All statistical calculations were performed using StatSoft, Inc. (2014) STATISTICA (data analysis software system), version 10. www.statsoft.com.

Parameters of aphid development and fecundity were analyzed using the Kruskal-Wallis test and post hoc multiple comparisons of mean ranks for all groups. Aphid preferences during settling were evaluated using Student $t$ test for independent samples. EPG parameters describing aphid probing behavior were calculated manually and individually for every aphid and the mean and standard errors were subsequently calculated using the EPG analysis Excel worksheet created by the authors for this study. Data thus obtained were analyzed by means of the KruskalWallis test and post hoc multiple comparisons of mean ranks for all groups.

Results of biochemical experiments are presented as means of triplicates for each variable. Data thus obtained were analyzed by means of the Kruskal-Wallis test and post hoc Newman-Keuls test.

\section{Results}

\section{Performance of aphid-free and aphid-infested plants under full-, low- and no-light conditions}

The mean values of indices used to measure plant tolerance to aphid infestation differed between FL and LL plants (Table 1). On FL plants, the number of aphids was significantly nearly five times higher than on LL plants. The values of the remaining indices did not differ significantly between FL and LL plants but certain trends were observed: plant weight index (WI) and tolerance index (TI) were 1.5 and 2.5 times lower on FL plants than on LL plants, respectively while the relative weight change (DWT) was twice as high. On NL plants, there was a rapid decline in aphid population during the experiment due to no reproduction and low survival. Therefore, these plants were excluded from analysis.

\section{Plant metabolic responses to aphid infestation under full-, low-, and no-light conditions}

Non-infested (AF) plants demonstrated distinct differences in the content of photosynthetic pigments, i.e., chlorophyll $\mathrm{a}$, chlorophyll b, and carotenoids (Table 2). These differences occurred between FL and LL and between FL and NL plants but not between LL and NL plants. The content of chlorophyll a was 6.5 and 5.0 times higher and the content of carotenoids was 10 and 20 times higher in FL plants than in LL and NL plants, respectively. Chlorophyll b was not detected in LL and NL plants while in FL plants, its content was $0.43 \mu \mathrm{g} \mathrm{g}^{-1}$ fresh weight (FW). In respect to saccharides and total phenolics contents, significant differences occurred also between FL and LL and between FL and NL plants but not between LL and NL plants. The content of saccharides was nearly three times higher and the content of phenolics was approximately 1.5 higher in FL plants than in LL and NL plants, respectively (Table 2). The activity of $\beta$-D-glucosidase was the highest in FL plants and the lowest in LL plants; in NL plants, the activity of $\beta$-D-glucosidase was higher than in LL plans but lower than in FL plants (Fig. 1).

In aphid-infested (AI) plants, similar trends occurred as far as the contents of photosynthetic pigments, saccharides, 
Table 1 Tolerance of Pisum sativum grown under full-light (FL) and low-light (LL) conditions to Acyrthosiphon pisum infestation

\begin{tabular}{lccc}
\hline & FL & LL & $p$ \\
\hline Number of aphids on plants & $62.29 \pm 9.47 \mathrm{a}$ & $13.14 \pm 2.89 \mathrm{~b}$ & $\underline{0.0022}$ \\
Weight index (WI) & $0.45 \pm 1.77$ & $3.06 \pm 2.38$ & 0.2502 \\
Relative weight change (DWT) & $14.49 \pm 8.27$ & $2.18 \pm 12.56$ & 0.8983 \\
Tolerance index (TI) & $0.27 \pm 0.14$ & $0.42 \pm 0.97$ & 0.3711 \\
\hline
\end{tabular}

Underlined value of $p$ indicates significant difference

Table 2 Content of photosynthetic pigments (chlorophyll a, chlorophyll b, carotenoids), total saccharides and total phenolics in aphid-free (AF) and aphid-infested (AI) Pisum sativum plants grown under full-light (FL), low-light (LL), and no-light (NL) conditions

\begin{tabular}{llllll}
\hline & $\begin{array}{l}\text { Chlorophyll a } \\
\left(\mathrm{mg} \cdot \mathrm{g}^{-1} \mathrm{FW}\right)\end{array}$ & $\begin{array}{l}\text { Chlorophyll b } \\
(\mathrm{mg} \cdot \\
\left.\mathrm{g}^{-1} \mathrm{FW}\right)\end{array}$ & $\begin{array}{l}\text { Carotenoids } \\
\left(\mathrm{mg} \cdot \mathrm{g}^{-1} \mathrm{FW}\right)\end{array}$ & $\begin{array}{l}\text { Saccharides }(\mathrm{mg} \\
\left.\text { glucose } \cdot \mathrm{g}^{-1} \mathrm{FW}\right)\end{array}$ & $\begin{array}{l}\text { Phenolics }(\mu \mathrm{g} \text { chlorogenic } \\
\left.\mathrm{acid} \cdot \mathrm{g}^{-1} \mathrm{FW}\right)\end{array}$ \\
\hline Effect of different light conditions & & & & \\
AF-FL & $1.17 \pm 0.22 \mathrm{a}$ & $0.43 \pm 0.12 \mathrm{a}$ & $0.21 \pm 0.04 \mathrm{a}$ & $0.26 \pm 0.06 \mathrm{a}$ & $25.00 \pm 4.01 \mathrm{a}$ \\
AF-LL & $0.18 \pm 0.00 \mathrm{~b}$ & $0.00 \pm 0.00 \mathrm{~b}$ & $0.02 \pm 0.00 \mathrm{~b}$ & $0.10 \pm 0.02 \mathrm{~b}$ & $16.62 \pm 4.01 \mathrm{~b}$ \\
AF-NL & $0.23 \pm 0.01 \mathrm{~b}$ & $0.00 \pm 0.00 \mathrm{~b}$ & $0.01 \pm 0.00 \mathrm{~b}$ & $0.09 \pm 0.02 \mathrm{~b}$ & $20.37 \pm 4.82 \mathrm{~b}$ \\
AI-FL & $1.09 \pm 0.11 \mathrm{a}$ & $0.41 \pm 0.05 \mathrm{a}$ & $0.26 \pm 0.01 \mathrm{a}$ & $0.11 \pm 0.01 \mathrm{a}$ & $27.73 \pm 4.82 \mathrm{a}$ \\
AI-LL & $0.21 \pm 0.01 \mathrm{~b}$ & $0.00 \pm 0.00 \mathrm{~b}$ & $0.02 \pm 0.00 \mathrm{~b}$ & $0.06 \pm 0.01 \mathrm{a}$ & $20.40 \pm 4.01 \mathrm{~b}$ \\
AI-NL & $0.18 \pm 0.01 \mathrm{~b}$ & $0.00 \pm 0.00 \mathrm{~b}$ & $0.01 \pm 0.00 \mathrm{~b}$ & $0.07 \pm 0.02 \mathrm{a}$ & $17.86 \pm 3.20 \mathrm{~b}$ \\
Effect of aphid infestation & & & & $25.00 \pm 4.01 \mathrm{a}$ \\
AF-FL & $1.17 \pm 0.22 \mathrm{a}$ & $0.43 \pm 0.12 \mathrm{a}$ & $0.21 \pm 0.04 \mathrm{a}$ & $0.26 \pm 0.06 \mathrm{a}$ & $27.73 \pm 4.82 \mathrm{a}$ \\
AI-FL & $1.09 \pm 0.11 \mathrm{a}$ & $0.41 \pm 0.05 \mathrm{a}$ & $0.26 \pm 0.01 \mathrm{a}$ & $0.11 \pm 0.01 \mathrm{~b}$ & $16.62 \pm 4.01 \mathrm{a}$ \\
AF-LL & $0.18 \pm 0.00 \mathrm{a}$ & $0.00 \pm 0.00$ & $0.02 \pm 0.00 \mathrm{a}$ & $0.10 \pm 0.02 \mathrm{a}$ & $20.40 \pm 4.01 \mathrm{a}$ \\
AI-LL & $0.21 \pm 0.01 \mathrm{a}$ & $0.00 \pm 0.00$ & $0.02 \pm 0.00 \mathrm{a}$ & $0.06 \pm 0.01 \mathrm{a}$ & $20.37 \pm 4.82 \mathrm{a}$ \\
AF-NL & $0.23 \pm 0.01 \mathrm{a}$ & $0.00 \pm 0.00$ & $0.01 \pm 0.00 \mathrm{a}$ & $0.09 \pm 0.02 \mathrm{a}$ & $17.86 \pm 3.20 \mathrm{a}$ \\
AI-NL & $0.18 \pm 0.01 \mathrm{a}$ & $0.00 \pm 0.00$ & $0.01 \pm 0.00 \mathrm{a}$ & $0.07 \pm 0.02 \mathrm{a}$ &
\end{tabular}

Values represent means $(n=3) \pm \mathrm{SD}$; different letters in columns represent statistically significant differences at $p=0.05$ (Newman-Keuls test)

and total phenolics are concerned. The concentrations of these constituents in FL plants were the highest and differed significantly from LL and NL plants but no differences occurred between LL and NL plants. The activity of $\beta$-D-glucosidase was comparable in FL, LL, and NL plants (Table 2; Fig. 1). Statistical analysis showed significant differences in saccharides content and the activity of $\beta$-Dglucosidase between non-infested (AF) and infested (AI) plants under full-light (FL) conditions. Under LL and NL conditions, no differences occurred in any measured constituent between AF and AI plants (Table 2; Fig. 1).

\section{Aphid performance, settling preferences, and probing behavior on plants grown under full-, low-, and no-light conditions}

The mean duration of pre-reproductive period of A. pisum on $P$. sativum was approximately seven to eight days irrespective of the treatment (Table 3). However, all the remaining demographic parameters analyzed differed among experimental variants: significant differences were found between
FL and LL, FL and NL plants but not between LL and NL plants. The duration of the reproductive period of aphids on LL and NL plants was extremely short and lasted usually 1 day, which was eight times shorter than on FL plants. Mature aphids on LL and NL plants gave birth to 2-3 nymphs on average during that period and died almost immediately, while on FL plants, a female had more than 40 nymphs and lived more than three days after the reproductive period, on average. The lifespan of aphids on LL and NL plants did not exceed 14 days, while on FL plants, all aphids lived beyond that period. On LL and NL plants, aphid survival declined rapidly from the sixth and seventh day of experiment, respectively (Fig. 2). In consequence, the values of the calculated life table parameters for aphids on FL plants were noticeably greater than those on LL and NL plants: the intrinsic rate of increase and net reproduction were more than four and 16 times higher, respectively (Table 3 ).

Generally, when given a free choice, the pea aphids preferred to settle on leaves from plants grown under FL conditions than on LL or NL plants. The pea aphids did not discriminate between FL and LL leaves during the first 


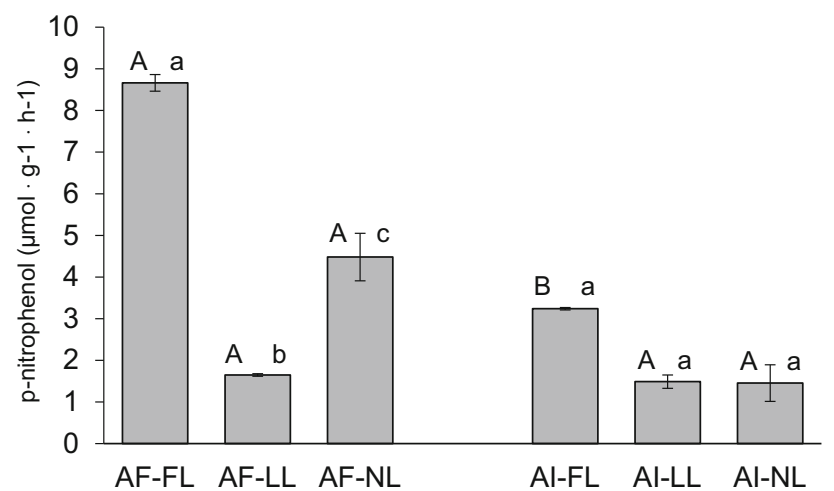

Fig. 1 Activity of $\beta$-D-glucosidase in aphid-free (AF) and aphidinfested (AI) Pisum sativum under different light conditions (FLfull-light, LL-low-light, NL-no-light). Capital letters indicate the effect of Acyrthosiphon pisum infestation on plant responses under FL, LL, and NL conditions (different letters denote statistically significant differences between $\mathrm{AF}$ and $\mathrm{AI}$ plants under a given light regime at $p<0.05$; Newman-Keuls test). Small letters show the effect of different light regimes on $P$. sativum (different letters denote statistically significant differences among $\mathrm{AF}$ and $\mathrm{AI}$ plants at $p<0.05$; Newman-Keuls test)

hour of the experiment but during the second hour, twice as many aphids settled on FL leaves than on LL leaves. At the end of the monitoring, i.e., $24 \mathrm{~h}$ after exposure, $75 \%$ of aphids chose FL leaves against LL leaves. In the case of NL leaves, the proportion of aphids that rejected those leaves in favor to FL leaves increased from $77 \%$ during the first hour to $85 \%$ after $24 \mathrm{~h}$ (Fig. 3).

The EPG monitoring of the pea aphid probing behavior (eighteen selected variables are shown in Table 4) revealed that on FL plants, the non-probing and the non-phloem and phloem probing phases were 20,40 , and $40 \%$ of the recording time, respectively (phloem phase index $=0.6$ ). In contrast, on LL plants, the non-probing, non-phloem, and phloem phases were $37.5,47.5$, and $15 \%$ of the recording time, respectively (phloem phase index $=0.3$ ); while on NL plants-52.5, 40, and $7.5 \%$ of the recording time, respectively (phloem phase index $=0.3$ ). The phloem salivation index was the highest in aphids on NL plants and the lowest on FL plants (Table 4, variables 1-5). In aphids on FL plants, the activities related to pathway and phloem phases were the main behaviors during the 8-h recording, while in aphids on LL and NL plants, pathway activities and non-probing prevailed. Especially, on NL plants, the duration phloem phase was very low and never exceeded $15 \%$ of time at any hour, making the pathway phase and non-probing phase the main aphid activities during the 8-h monitoring (from 20 in the beginning to $65 \%$ at the end and 35 at the beginning to $70 \%$ at the end of recording, respectively) (Fig. 4). Probing activities on all plants were divided into several probes, but there were twice as many probes on LL and NL plants than on FL plants. In consequence, the average duration of a probe was nearly five and six times longer on FL than on LL and NL plants, respectively. The number of probes that did not go beyond epidermis and/or outer layer of mesophyll cells (i.e., shorter than $3 \mathrm{~min}$ ) was twice as high on LL and NL plants than on FL plants. (Table 4, variables 6-8). The probes in FL, LL, and NL plants contained a similar number of standard cell punctures but the average number of repetitive cell punctures associated with probing in sieve elements was significantly higher in FL plants than in LL and NL plants (Table 4, variables 9-10). On FL plants, more than $80 \%$ of aphids reached sieve elements, while on LL and NL plants60 and 30\%, respectively. All aphids that reached phloem on FL plants ingested sap in a sustained way, while on LL and NL plants, $37 \%$ of aphids failed to feed (Fig. 5; Table 4, variables 11-12). The time to the first probe and the duration of the first probe were similar in all aphids. During the period preceding the first contact with sieve elements, aphids punctured plants approximately three times more frequently on LL and NL plants than on FL plants. The time to the first phloem phase from the onset of probing on FL plants was 2.0 and $3.3 \mathrm{~h}$ shorter than on LL and NL plants, respectively (Table 4, variables 13-18).

\section{Discussion}

The results of the present study show that, predictably, light deprivation caused a dramatic decrease in the vitality of the pea plants, which was manifested in the decline in
Table 3 Population and life table parameters of apterous Acyrthosiphon pisum on Pisum sativum grown under full-light (FL), low-light (LL), and nolight (NL) conditions

\begin{tabular}{lcll}
\hline & FL & LL & NL \\
\hline Pre-reproductive period (days) & $6.94 \pm 0.31$ & $7.88 \pm 0.58$ & $6.94 \pm 0.37$ \\
Reproductive period (days) & $7.75 \pm 0.95 \mathrm{a}$ & $0.81 \pm 0.26 \mathrm{~b}$ & $0.56 \pm 0.26 \mathrm{~b}$ \\
Post-reproductive period (days) & $3.31 \pm 0.35 \mathrm{a}$ & $1.25 \pm 0.48 \mathrm{~b}$ & $0.63 \pm 0.27 \mathrm{~b}$ \\
Daily fecundity (number of nymphs/aphid) & $5.42 \pm 0.20 \mathrm{a}$ & $1.56 \pm 0.50 \mathrm{~b}$ & $1.38 \pm 0.60 \mathrm{~b}$ \\
Total fecundity (number of nymphs/aphid) & $42.06 \pm 5.34 \mathrm{a}$ & $2.69 \pm 0.99 \mathrm{~b}$ & $1.94 \pm 0.90 \mathrm{~b}$ \\
Intrinsic rate of natural increase $r_{\mathrm{m}}$ & $0.41 \pm 0.03 \mathrm{a}$ & $0.09 \pm 0.03 \mathrm{~b}$ & $0.04 \pm 0.02 \mathrm{~b}$ \\
Net reproduction $R_{0}$ & $42.06 \pm 5.34 \mathrm{a}$ & $3.25 \pm 1.36 \mathrm{~b}$ & $1.75 \pm 0.77 \mathrm{~b}$ \\
Mean time of generation development $T$ & $11.04 \pm 0.32 \mathrm{a}$ & $4.28 \pm 1.18 \mathrm{~b}$ & $2.57 \pm 0.99 \mathrm{~b}$ \\
\hline
\end{tabular}

Values are mean $\pm \mathrm{SE}$ from 16 replicates per treatment. Different lowercase letters in rows indicate statistically significant differences among treatments according to Kruskal-Wallis test $(p<0.05)$ 

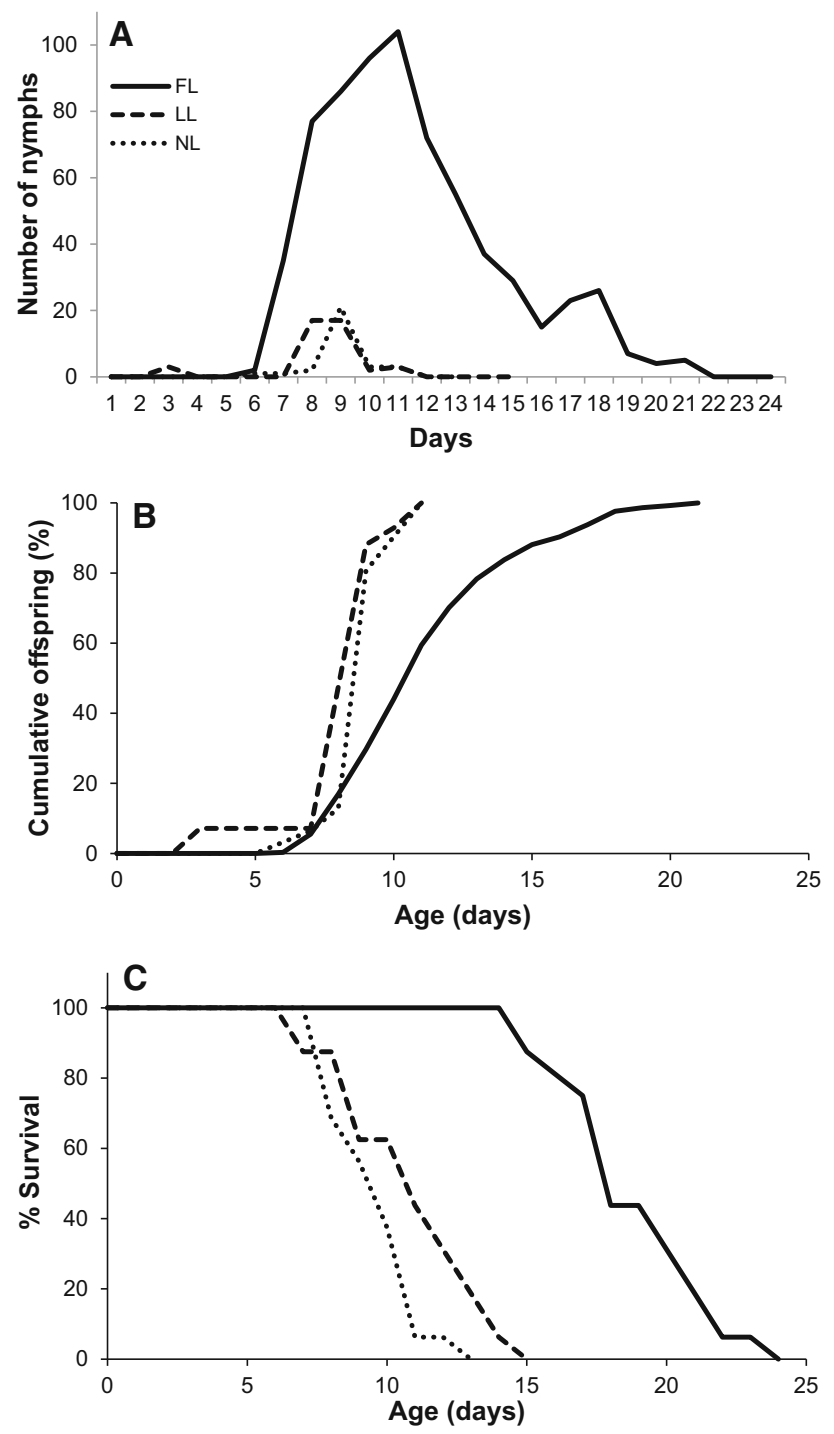

Fig. 2 Total number of nymphs per day (A), cumulative offspring (B) and survival (C) of apterous Acyrthosiphon pisum on Pisum sativum grown under full-light (FL), low-light (LL), and no-light (NL) conditions

basic metabolic indicators measured. The contents of photosynthetic pigments and saccharides in peas grown under the full-light (FL) laboratory conditions in the current study were typical of the species under natural conditions (e.g., Hattab et al. 2009). As expected, in LL and NL plants in comparison to FL plants, the quantities of photosynthetic pigments and saccharides were much lower. Similar trends occurred in the activity of $\beta$-D-glucosidase that dropped significantly in light-deprived plants. The deficit of light caused also a significant decrease in the content of phenolics (Table 2; Fig. 1). Among the secondary metabolites, plant phenolics constitute the most widespread and multifunctional group of defensive compounds (Boudet 2007; Vermerris and Nicolson 2008). They play manifold roles as the elements of the constitutive

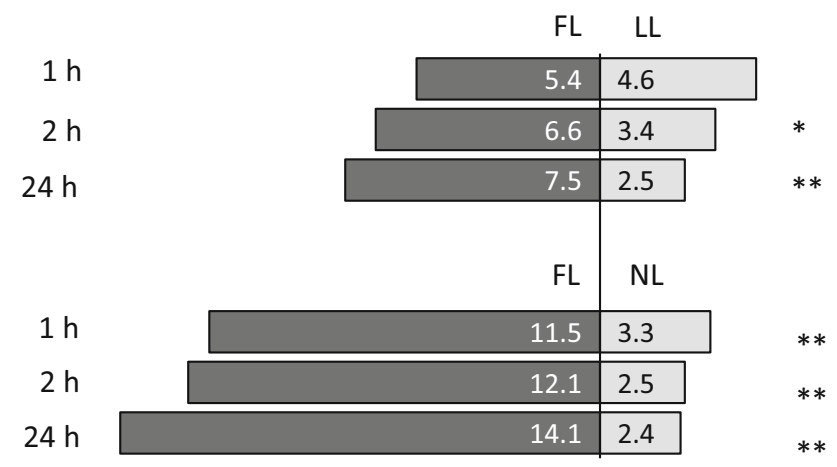

Fig. 3 Preferences of Acyrthosiphon pisum during settling on Pisum sativum when given a choice between leaves from plants grown under full-light (FL), low-light (LL), and no-light (NL) conditions. Numbers represent the mean number of aphids that settled 1, 2, and $24 \mathrm{~h}$ after access to the leaves. Asterisks indicate statistically significant differences (Student $t$ test, ${ }^{*} p<0.01,{ }^{* *} p<0.001$ )

defense system as well as the induced plant responses to abiotic and biotic stresses (Bennett and Walsgrove 1994; Kaplan et al. 2008; Bhattacharya 2010; Cheynier et al. 2013). As is the case with many secondary metabolites, the concentration of phenolics in plant tissues depends on environmental conditions and the metabolic status of the plant (Caretto et al. 2015). The pathway of phenolic biosynthesis is under tight developmental control and multiple environmental conditions, with light and hormones being the best investigated (Irani et al. 2003). Moreover, it has been shown that the changes in level of sugars in plant tissues may determine the intensity of different biochemical paths, including secondary metabolism via which phenolics are synthesized (Morkunas et al. 2005, 2011). It is known that biotic and abiotic stresses stimulate carbon fluxes from the primary to the secondary metabolic pathways thus inducing a shift of the available resources in favor of the synthesis of secondary products (Lattanzio 2013). If there is no constraint caused by nutrient deficiency, the level of photosynthesis might affect the biosynthesis of carbohydrates and C-based defense compounds (such as phenols), as suggested by the carbon/ nitrogen balance theory (Bryant et al. 1983). Additionally, the level of irradiation has direct impact on the biosynthesis of phenolics (Ibrahim and Jaafar 2012). For example, an increased accumulation of phenolic compounds in response to an excess of UV-B radiation has been demonstrated. These metabolites limit penetration of UV radiation through the epidermis, acting as a peculiar filter: flavonoids protect DNA and photosynthetic apparatus of cells by reducing UV-B (Feng et al. 2007; Jansen et al. 2012) and have antioxidant activity (Jansen et al. 2008).

The impact of aphid infestation on plants grown under different light conditions varied depending on the treatment (Table 1). Generally, plants grown under full-light 
Table 4 Probing behavior of Acyrthosiphon pisum on Pisum sativum grown under full (FL), low (LL), and no-light (NL) conditions

\begin{tabular}{|c|c|c|c|c|c|}
\hline No & EPG variable & FL & LL & NL & $\mathrm{p}$ \\
\hline & General aspects of aphid probing behavior & & & & \\
\hline 1 & Total duration of non-probing (h) & $1.6 \pm 0.5(n=21) \mathrm{a}$ & $3.0 \pm 0.6(n=16) \mathrm{b}$ & $4.2 \pm 0.7(n=14) \mathrm{b}$ & 0.0011 \\
\hline 2 & $\begin{array}{l}\text { Total duration of non-phloem probing phase } \\
(\mathrm{h})^{\mathrm{a}}\end{array}$ & $3.2 \pm 0.4(n=21)$ & $3.78 \pm 0.5(n=16)$ & $3.2 \pm 0.6(n=14)$ & 0.5451 \\
\hline 3 & Total duration of phloem phase $(\mathrm{h})^{\mathrm{b}}$ & $3.1 \pm 0.5(n=21) \mathrm{a}$ & $1.2 \pm 0.4(n=16) \mathrm{ab}$ & $0.6 \pm 0.4(n=14) \mathrm{b}$ & 0.0022 \\
\hline 4 & Phloem phase index ${ }^{\mathrm{cd}}$ & $0.6 \pm 0.1(n=17) \mathrm{a}$ & $0.3 \pm 0.1(n=10) \mathrm{ab}$ & $0.3 \pm 0.2(n=4) \mathrm{ab}$ & 0.0452 \\
\hline 5 & Phloem salivation index ${ }^{\text {de }}$ & $0.1 \pm 0.0(n=17)$ & $0.2 \pm 0.1(n=10)$ & $0.5 \pm 0.3(n=4)$ & 0.2171 \\
\hline 6 & Number of probes & $14.7 \pm 3.0(n=21) \mathrm{a}$ & $34.2 \pm 4.5(n=16) \mathrm{b}$ & $27.7 \pm 5.5(n=14) \mathrm{ab}$ & 0.0016 \\
\hline 7 & Number of probes $<3 \mathrm{~min}$ & $8.1 \pm 1.9(n=21) \mathrm{a}$ & $17.7 \pm 2.6(n=16) \mathrm{b}$ & $15.4 \pm 3.7(n=14) \mathrm{ab}$ & 0.0051 \\
\hline 8 & Mean duration of a probe (min) & $46.7 \pm 12 .(n=21) \mathrm{a}$ & $9.9 \pm 1.4(n=16) \mathrm{b}$ & $8.5 \pm 1.2(n=14) \mathrm{ab}$ & 0.0000 \\
\hline 9 & Number of standard cell punctures & $176.3 \pm 23.5(n=21)$ & $221.8 \pm 25.5(n=16)$ & $166.4 \pm 30.4(n=14)$ & 0.3214 \\
\hline 10 & Number of repetitive cell punctures & $30.9 \pm 5.7(n=21) \mathrm{a}$ & $12.3 \pm 4.0(n=16) \mathrm{b}$ & $2.4 \pm 1.8(n=14) \mathrm{b}$ & 0.0001 \\
\hline 11 & Proportion of aphids with phloem phase & $0.8 \pm 0.1(n=21) \mathrm{a}$ & $0.6 \pm 0.1(n=16) a b$ & $0.3 \pm 0.1(n=14) \mathrm{b}$ & 0.0086 \\
\hline \multirow[t]{2}{*}{12} & $\begin{array}{l}\text { Proportion of aphids with sustained sap } \\
\text { ingestion phase E } 2>10 \mathrm{~min}\end{array}$ & $0.8 \pm 0.1(n=21) \mathrm{a}$ & $0.4 \pm 0.1(n=16) \mathrm{ab}$ & $0.2 \pm 0.1(n=14) \mathrm{b}$ & 0.0005 \\
\hline & $\begin{array}{l}\text { Activities in peripheral tissues before the first } \\
\text { phloem phase }\end{array}$ & & & & \\
\hline 13 & Time to the first probe (min) & $3.7 \pm 1.0(n=21) \mathrm{a}$ & $9.2 \pm 3.2(n=16) \mathrm{ab}$ & $3.0 \pm 0.8(n=14)$ ac & 0.0021 \\
\hline 14 & Duration of the first probe (min) & $5.3 \pm 4.5(n=21)$ & $1.1 \pm 0.8(n=16)$ & $5.4 \pm 4.8(n=14)$ & 0.3056 \\
\hline 15 & Number of probes before first phloem phase $\mathrm{E} 1^{\mathrm{f}}$ & $8.9 \pm 2.8(n=21) \mathrm{a}$ & $27.3 \pm 4.7(n=16) \mathrm{b}$ & $23.8 \pm 5.7(n=14) a b$ & 0.0000 \\
\hline 16 & $\begin{array}{l}\text { Number of probes }<3 \text { min. before first phloem } \\
\text { phase }^{\text {f }}\end{array}$ & $5.8 \pm 1.8(n=21) \mathrm{a}$ & $14.6 \pm 2.8(n=16) \mathrm{b}$ & $12.7 \pm 3.6(n=14) \mathrm{ab}$ & 0.0026 \\
\hline 17 & Time to the first phloem phase E1 $(h)^{\mathrm{f}}$ & $3.3 \pm 0.6(n=21) \mathrm{a}$ & $5.5 \pm 0.7(n=16) \mathrm{ab}$ & $6.9 \pm 0.7(n=14) \mathrm{b}$ & 0.0049 \\
\hline 18 & $\begin{array}{l}\text { Time to the first sustained phloem sap ingestion } \\
\text { E2 }>10^{\mathrm{f}}(\mathrm{h})\end{array}$ & $3.9 \pm 0.6(n=21) \mathrm{a}$ & $5.9 \pm 0.7(n=16) \mathrm{ab}$ & $7.2 \pm 0.5(n=14) \mathrm{b}$ & 0.0013 \\
\hline
\end{tabular}

Values represent mean \pm SE, $n=$ number of replicates, different letters in rows indicate statistically significant differences among treatments at $p<0.05$ (Kruskal-Wallis test)

a Non-phloem probing phase includes activities: pathway with cell punctures 'pd'(C), derailed stylet activities (F), and xylem phase (G)

${ }^{b}$ Phloem phase includes activities: salivation into sieve elements (E1) and sap ingestion (E2)

${ }^{c}$ Phloem phase index was calculated according to the formula: $(\mathrm{E} 1+\mathrm{E} 2) /(\mathrm{C}+\mathrm{E} 1+\mathrm{E} 2+\mathrm{G}+\mathrm{F})$

${ }^{\mathrm{d}}$ Only the individuals that showed phloem phase were included in analysis

e Phloem salivation index was calculated according to the formula: E1/(E1 + E2)

${ }^{\mathrm{f}}$ All individuals were included in analysis; when an aphid did not show phloem phase, the time/number of probes to 1st E1 or 1st E2 was the time/number of probes until the end of experiment

conditions appeared much more tolerant to aphid infestation than plants grown under low-light conditions, which might have been the effect of the ability of peas to compensate for damage caused by aphid feeding, given favorable growing conditions. Such phenomenon was described in wheat and Russian wheat aphid Diuraphis noxia (Mordvilko) by HengMoss et al. (2003). Nevertheless, at metabolic level, clear effects of aphid feeding were observed (Table 2). However, the potency of plant responses was related to the variation in light intensity level-aphid infestation combination. The most visible effects occurred on FL plants. In aphid-infested plants, the amount of photosynthetic pigments remained unaltered. However, a twofold decrease in saccharides content occurred. The decline in saccharides quantity might have been the effect of aphid feeding: the supply of glucose due to photosynthesis was probably too low in relation to the removal of sugars with phloem sap by the aphids. Morkunas et al. (2016) revealed that in leaves infested by 30 aphids the reduced sucrose level was observed up to $48 \mathrm{~h}$, which was accompanied by a considerable increase in the expression level of the PSSUT1 gene encoding the sucrose transporter. At the same time, an increase in the total pool of flavonoids and the synthesis of pisatin in leaf cells of $P$. sativum after $48 \mathrm{~h}$ of A. pisum infestation were preceded $(0-24 \mathrm{~h})$ by a considerable reduction in the levels of sucrose and fructose in comparison to the control.

The activity of $\beta$-D-glucosidase was affected by both, aphid infestation and deficit of light (Fig. 1). However, it 

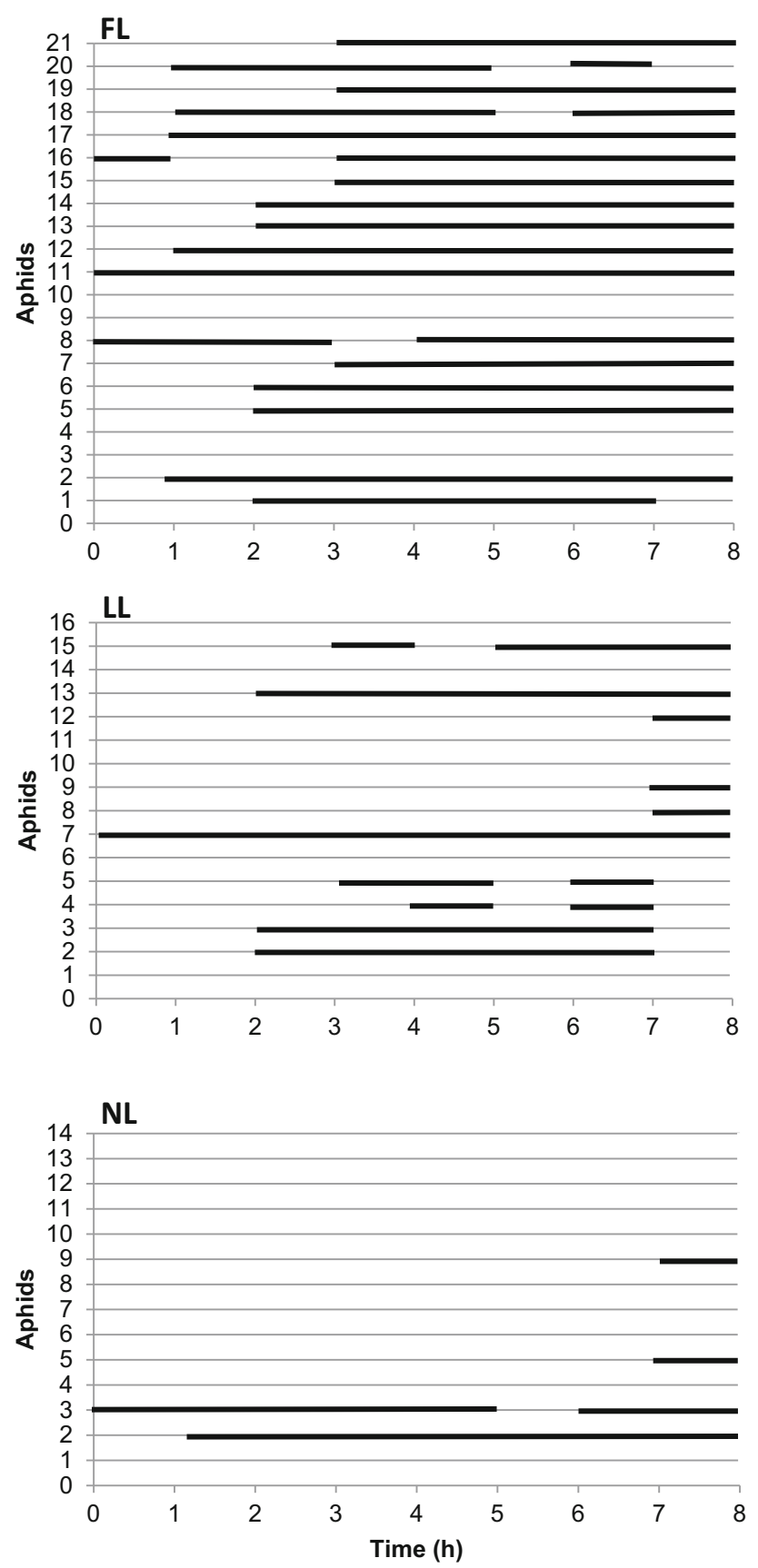

Fig. 4 Feeding success of individual Acyrthosiphon pisum $(n=$ 14-21) during 8-h monitoring on Pisum sativum grown under fulllight (FL), low-light (LL), and no-light (NL) conditions. Solid lines represent periods of phloem sap ingestion E2

appears that these factors acted differently depending on the light regime. In full light, the reduction in metabolic intensity was the apparent reaction of plant to aphid infestation. Detailed studies by Woźniak et al. (2016) revealed that pea aphid infestation caused a decline in $\beta$-Dglucosidase activity in peas from the $48 \mathrm{~h}$ after infestation under optimal light conditions and that the enzyme activity in leaves infested by A. pisum was lower than in non-
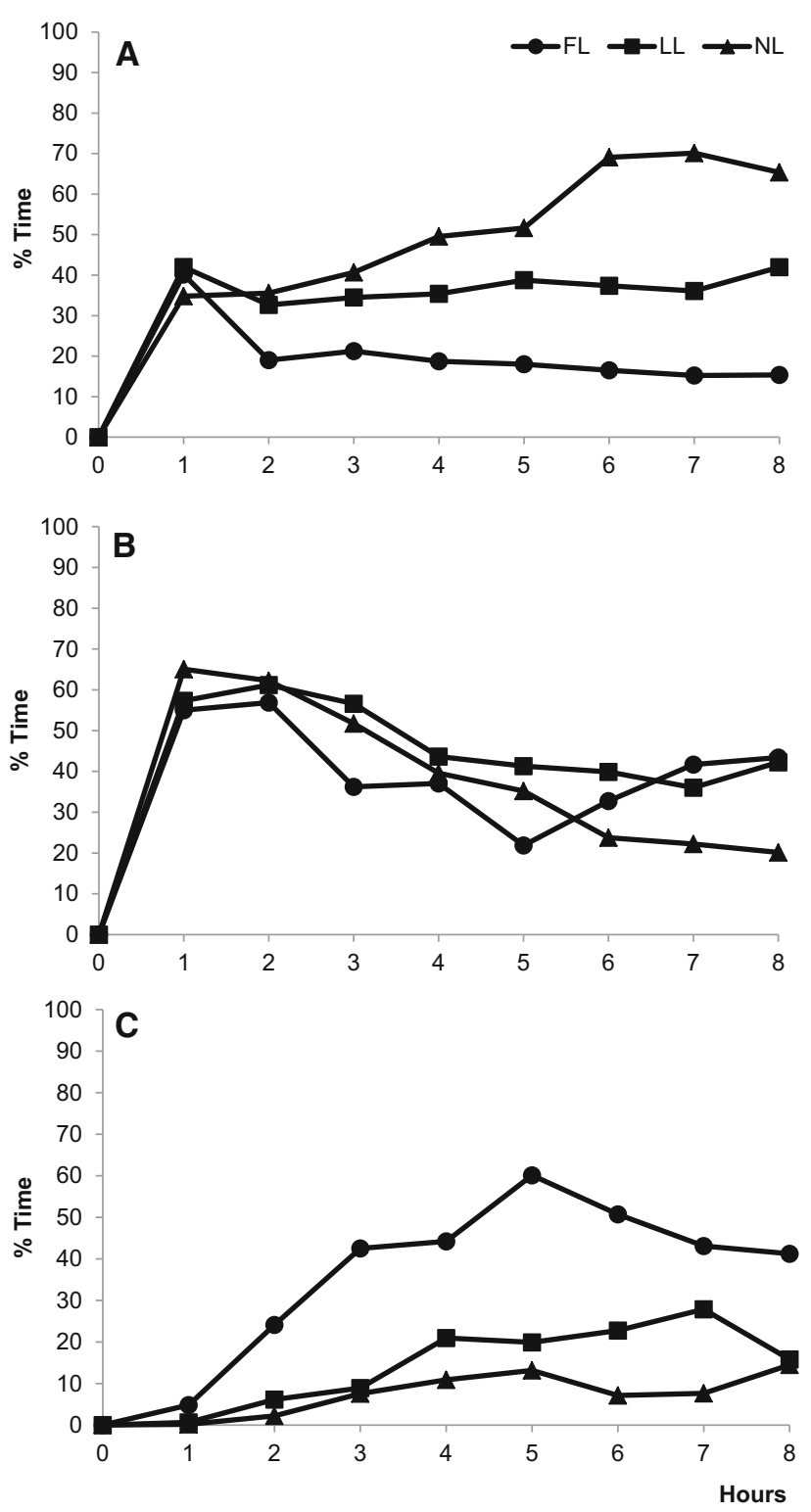

Fig. 5 Sequential changes in Acyrthosiphon pisum probing behavior on Pisum sativum grown under full-light (FL), low-light (LL), and nolight (NL) conditions expressed as proportion of time assigned to nonprobing (A), probing in non-phloem tissues $(\mathbf{B})$, and phloem phase (C) activities

infested leaves. On the other hand, under low-light or nolight conditions, the drop in $\beta$-D-glucosidase activity was most likely due to the low level of metabolism in consequence of inadequate conditions for photosynthesis, like the low amount of photosynthetic pigments, which occurred in the present study. Plant $\beta$-glucosidases participate in a variety of metabolic events, including phytohormone activation, activation of metabolic intermediates, cell wall remodeling, and lignification (Esen 1993). Also, this enzyme hydrolyses isoflavone glucosides in plant cells (Morkunas et al. 2005). Therefore, the activity of this 
enzyme is often used as a biochemical indicator in research on plant metabolic status under different experimental situations. Pentzold et al. (2013) reported that insect herbivory is often restricted by glucosylated plant chemical defense compounds that are activated by plant $\beta$-glucosidases to release toxic aglycones upon plant tissue damage. The stimulation of the enzyme activity in bird cherry (Prunus padus L.) leaves as a result of Rhopalosiphum padi (L.) feeding was demonstrated by Sytykiewicz (2008).

Here, we demonstrated that infestation by $A$. pisum caused a decrease in the content of saccharides (AI-FL in relation to AF-FL). Also, $\beta$-D-glucosidase activity in leaves infested by aphids cultured in FL and NL (AI-FL and AINL) was lower than in aphid-free leaves (variant AF-FL and AF-NL)(Table 2). In turn, pea aphid feeding did not cause changes in content of photosynthetic pigments in leaves in relation to aphid-free leaves. The very low metabolic level in LL and NL plants was probably the reason that in these plants no significant effects of aphid infestation on plant biochemical parameters measured occurred. It is also likely that aphid feeding on these plants was very limited in comparison to FL plants, as explained later.

In contrast to the weak plant response on the parameters measured here to aphid infestation under any light conditions applied in the experiments, aphid response to plants deprived of light was very strong and clear. The values of demographic and life table parameters of A. pisum on FL plants (Fig. 2; Table 3) were typical for this species on $P$. sativum under preferable environmental conditions and similar to the values reported by other authors (e.g., Legrand and Barbosa 2000; Goławska 2010; Joschinsky et al. 2015). Likewise, the probing and feeding behaviors of the pea aphid (Table 4) were representative for the species under given favorable conditions on peas (e.g., Kordan et al. 2012). Generally, on FL plants, the proportion of phloem phase during probing was the highest, and the contribution of salivation during phloem phase was the lowest. The differences in behavior between aphids on plants grown under different light conditions occurred before the phloem phase and also during the phloem phase. The reluctance to continue probing beyond subepidermal layer, and in consequence the failure in reaching phloem vessels, might have caused the malnutrition and premature death in aphids on LL and NL plants. The termination of probes before reaching sieve elements may be attributed to two factors: the presence of phagodeterrents and/or the lack of phagostimulants. The presence of phagodeterrents in mesophyll cells was not a likely cause: in light-deprived plants, the level of phenolics was lower than in plants grown under full-light availability. At the same time, in LL and NL plants, the activity of $\beta$-D-glucosidase was low. In parallel with their basic diverse physiological functions in plant cells, $\beta$-glucosidases are 'detonators of plant chemical defenses' in so-called two-component plant chemical defense system (Morant et al. 2008; Pentzold et al. 2014). In this role, $\beta$-glucosidases activate plant chemical defense compounds that are stored in cells as glycosides, by hydrolysing the $\beta$-glucosidic bond between a carbohydrate and an aglycone moiety thus releasing active plant toxins (Morant et al. 2008). $\beta$-glucosidases and glucosylated defense compounds are stored in different cell compartments, therefore cell/tissue damage is required for the release of the toxic aglucone. Aphids evolved a mechanism to circumvent this plant defense system. By leading their stylets within cell walls of tissues that separate them from phloem sieve elements, aphids do not damage the cells (Tjallingii and Hogen Esch 1993). The plant cells remain intact also after brief punctures that aphids make for gustatory purposes (Pettersson et al. 2007). The presence of phagostimulants in cortical tissues of plants, however, is essential for the continuation of probing. Hewer et al. (2011) demonstrated that low sucrose concentrations in vacuoles may provoke aphids to retract their stylets and probe another next cell until a favorable cell sap composition is encountered. Our findings are in accordance to the aforementioned concept. The present experiments showed that although the individual probes were significantly shorter on LL and NL plants than on FL plants, the probing activity was not impeded. Aphids repeatedly inserted stylets into plant tissues and were not restrained from puncturing cells adjacent to stylet route: the total number of cell punctures was similar in all plants. Therefore, aphids had the opportunity to evaluate the chemical composition of mesophyll cells (Table 4, variables 9-10). In addition, aphids that did reach phloem vessels on LL and NL plants terminated ingestion shortly (Table 4, variables 11-12; Figs. 4, 5). In the EPG experiment, aphid movements are limited to the small area of a leaf by the golden wire electrode that is attached to the body. It is likely that the aphids would have retreated from the LL and NL plants soon after few initial probes. Indeed, the free-choice experiment supports this hypothesis: few aphids were found to settle on LL and NL plants as early as $1 \mathrm{~h}$ after the access to plants (Fig. 3). The monitoring of aphid behavior during settling is used as a good indicator of plant suitability in evaluating the activity of exogenously applied compounds (Dancewicz et al. 2016).

Statistical analysis showed significant differences in probing behavior between aphids on FL and LL and between aphids on FL and NL plants but not between aphids on LL and NL plants. In full light, plants produced high amounts of sugars that might have stimulated aphid feeding. Glucose, the immediate product of photosynthesis is transported via phloem vessels after incorporation into sucrose (Liu et al. 2012; Braun et al. 2013). 
Here, we showed also how the applied light conditions affected the metabolic status of the host plant (Pisum sativum L. cv. Cysterski) and how it can be related to demographic parameters of pea aphid population (duration of pre-reproductive, reproductive, and post-reproductive periods and fecundity). Therefore, the results of the present study showed clearly that low irradiation or the lack of light caused a considerable limitation of the A. pisum population growth rate. The duration of the reproductive and post-reproductive periods of pea aphids on LL and NL plants was significantly shorter than on plants growing in full light (FL). Besides, the abovementioned factors inhibited daily fecundity of aphids.

As reported by Bale et al. (2002), abiotic factors such as temperature, $\mathrm{CO}_{2}$, UV-B and drought might directly affect herbivorous insects, just like the light conditions. Moreover, it has been showed by Awmack and Leather (2002) that host plant quality is a key determinant of the fecundity of herbivorous insects. Components of host plant quality (such as carbon, nitrogen, and defensive metabolites) directly affect the potential and the achieved herbivore fecundity. It has been documented that plant quality affects the larger-scale ecological interactions: most herbivorous insects interact with members of their own species, members of other species, and natural enemies, and all of these interactions have the potential to affect the fecundity of insect herbivores (Mooney et al. 2012; Dyer et al. 2013; Burkepile and Parker 2017).

The results of the present study showed that both, the lack of or insufficiency in light supply and aphid infestation had a profound effect on plant metabolic status. However, the potency of metabolic responses to these factors depended on the variation in light intensity level-aphid infestation combination, with light intensity level having a priority in this interaction. The increase in light intensity from complete darkness (NL) to the minimum level required for photoperiodic reaction (LL) did not stimulate evident changes in plant physiological status, irrespective of aphid infestation. Minimum light offered to plants was sufficient for plant survival but not sufficient for the nutrient production for aphids.

Open Access This article is distributed under the terms of the Creative Commons Attribution 4.0 International License (http://crea tivecommons.org/licenses/by/4.0/), which permits unrestricted use, distribution, and reproduction in any medium, provided you give appropriate credit to the original author(s) and the source, provide a link to the Creative Commons license, and indicate if changes were made.

\section{References}

Akemo MC, Regnier EE, Bennett MA (2000) Weed suppression in spring-sown rye (Secale cereale) - pea (Pisum sativum) cover crop mixes. Weed Technol 14:545-549
Akhter N, Rahman MM, Hasanuzzaman M, Nahar K (2009) Physiological response of garden pea (Pisum sativum L.) grown under different light environment. Bot Res Int 2:304-309

Awmack CS, Leather SR (2002) Host plant quality and fecundity in herbivorous insects. Annu Rev Entomol 47:817-844

Awmack CS, Leather SR (2007) Growth and development. In: Van Emden HF, Harrington R (eds) Aphids as crop pests. CAB International, wallingford, pp 135-151

Bale J, Masters GJ, Hodkinson ID, Awmack C, Bezemer TM, Brown V, Butterfield J, Buse A, Coulson JC, Farrar J, Good JG, Harrington R, Hartley S, Jones TH, Lindroth LL, Press MC, Symrnioudis I, Watt AD, Whittaker JB (2002) Herbivory in global climate change research: direct. Glob Change Biol 8:1-16

Bennett RN, Walsgrove RM (1994) Secondary metabolites in plant defense mechanisms. New Phytol 127:617-633

Bhattacharya A, Sood P, Citovsky V (2010) The roles of plant phenolics in defense and communication during Agrobacterium and Rhizobium infection. Mol Plant Pathol 11:705-719

Birch LC (1948) The intrinsic rate of natural increase of an insect population. J Anim Ecol 17(1):15-26

Björnesjö K (1955) Analysis of protein-bound serum polysaccharides with anthrone reagent. Scand J Clin Lab Inves 6:147-152

Blackman RL, Eastop VF (1985) Aphids on the world's crops: an identification guide. Wiley, Chichester

Boudet A-M (2007) Evolution and current status of research in phenolic compounds. Phytochemistry 68:2722-2735

Braun DM, Wang L, Ruan Y-L (2013) Understanding and manipulating sucrose phloem loading, unloading, metabolism, and signalling to enhance crop yield and food security. J Exp Bot 65(7):1713-1735. doi:10.1093/jxb/ert416

Broeke CJM, Dicke M, van Loon JJA (2013) Feeding behaviour and performance of different populations of the black currant-lettuce aphid, Nasonovia ribis-nigri, on resistant and susceptible lettuce. Entomol Exp Appl 148:130-141. doi:10.1111/eea.12084

Bryant JP, Chapin FS, Klein DR (1983) Carbon/nutrient balance of boreal plants in relation to vertebrate herbivory. Oikos 40:357-368

Burkepile DE, Parker JD (2017) Recent advances in plant-herbivore interactions. F1000 Res. doi:10.12688/f1000research.10313.1

Caretto S, Linsalata V, Colella G, Mita G, Lattanzio V (2015) Carbon fluxes between primary metabolism and phenolic pathway in plant tissues under stress. Int J Mol Sci 16:26378-26394

Chapagain T, Riseman A (2014) Barley-pea intercropping: effects on land productivity, carbon and nitrogen transformations. Field Crop Res 166:18-25

Cheynier V, Comte G, Davies KM, Lattanzio V, Martens S (2013) Plant phenolics: recent advances on their biosynthesis, genetics, and ecophysiology. Plant Physiol Bioch 72:1-20

Chory J (2010) Light signal transduction: an infinite spectrum of possibilities. Plant J 61:982-991. doi:10.1111/j.1365-313X. 2009.04105.x

Cupina B (2016) Legume companion cropping for increasing forage productivity in low input system. Adv Plants Agric Res 3(2):00087. doi:10.15406/apar.2016.03.00087

Dancewicz K, Sznajder K, Załuski D, Kordan B, Gabryś B (2016) Behavioral sensitivity of Myzus persicae to volatile isporenoids in plant tissues. Entomol Exp Appl 160:229-240

Dyer LA, Richards LA, Short SA, Dodson CD (2013) Effects of $\mathrm{CO}_{2}$ and temperature on tritrophic interactions. PLoS ONE 8(4):e62528. doi:10.1371/journal.pone.0062528

Eckstein A, Zięba P, Gabryś H (2012) Sugar and light effects on the condition of the photosynthetic apparatus of Arabidopsis thaliana cultured in vitro. J Plant Growth Regul 31:90-101. doi:10.1007/s00344-011-9222-z

Elliott WM, Miller JH (1974) Light-controlled stem elongation in pea seedlings grown under varied light conditions. Plant Physiol $53: 279-283$ 
Esen A (1993) $\beta$-Glucosidase overview. In: Esen A (ed) bGlucosidases: biochemistry and molecular biology. ACS Symposium Series 533. American Chemical Society, Washington, DC, pp 1-14

Feng R, Ni HM, Wang SY, Tourkova IL, Shurin MR, Harada H, Yin XM (2007) Cyanidin-3-rutinoside, a natural polyphenol antioxidant, selectively kills leukemic cells by induction of oxidative stress. J Biol Chem 282:13468-13476

Formela M, Samardakiewicz S, Marczak Ł, Nowak W, Narożna D, Bednarski W, Kasprowicz-Maluśki A, Morkunas I (2014) Effects of endogenous signals and Fusarium oxysporum on the mechanism regulating genistein synthesis and accumulation in yellow lupine and their impact on plant cell cytoskeleton. Molecules. doi:10.3390/molecules190x0000x

Garg N, Singla R (2004) Growth, photosynthesis, nodule nitrogen and carbon fixation in the chickpea cultivars under salt stress. Braz $\mathrm{J}$ Plant Physiol 16:137-146

Gawronska H, Yang Y-Y, Furukawa K, Kendrick RE, Takahashi N, Kamiya Y (1995) Effects of low irradiance stress on gibberellin levels in pea seedlings. Plant Cell Physiol 36:1361-1367

Givnish TJ (1988) Adaptation to sun and shade: a whole-plant perspective. Aust J Plant Physiol 15:63-92

Goławska S (2010) Effect of various host-plants on the population growth and development of the pea aphid. J Plant Prot Res 50(2):224-228

Goławska S, Łukasik I (2009) Acceptance of low-saponin lines of alfalfa with varied phenolic concentrations by pea aphid (Homoptera: Aphididae). Biol Sect Zool 64:377-382

Goławska S, Łukasik I (2012) Antifeedant activity of luteolin and genistein against the pea aphid, Acyrthosiphon pisum. J Pest Sci 85:443-450. doi:10.1007/s10340-012-0452-z

Goławska S, Krzyżanowski R, Łukasik I (2010) Relationship between aphid infestation and chlorophyll content in Fabaceae species. Acta Biol Cracov Bot 52(2):76-80

Gyulay P, Schaferz E, Nagy F (2003) Light perception and signalling in higher plants. Curr Opin Plant Biol 6:446-452

Hardie J, Holyoak M, Taylor NJ, Griffiths DC (1992) The combination of electronic monitoring and video-assisted observations of plant penetration by aphids and behavioural effects of polygodial. Entomol Exp Appl 62:233-239

Hattab S, Dridi B, Chouba L, Kheder MB, Bousetta H (2009) Photosynthesis and growth responses of pea Pisum sativum L. under heavy metals stress. J Environ Sci 21:1552-1556

Helden M, Tjallingii WF (1993) Tissue localization of lettuce resistance to the aphid $N$. ribisnigri using electrical penetration graphs. Entomol Exp Appl 68:269-278

Heng-Moss TM, Ni X, Macedo T, Markwell JP, Baxendale FP, Quisenberry SS, Tolmay V (2003) Comparison of chlorophyll and carotenoid concentrations among Russian wheat aphid (Homoptera: Aphididae)-infested wheat isolines. J Econ Entomol 96(2):475-481

Hewer A, Becker A, van Bel A (2011) An aphids' Odyssey - the cortical quest for the vascular bundle. J Exp Biol 214:3868-3879

Hill MO (1999) Ellenberg's indicator values for british plants: technical annex (ECOFACT research report). Institute of Terrestrial Ecology, Huntingdon

Hiscox JD, Israelstam GF (1979) A method for the extraction of chlorophyll from leaf tissue without maceration. Can J Bot 57:1332-1334

Huňady I, Hochman M (2014) Potential of legume-cereal intercropping for increasing yields and yield stability for self-sufficiency with animal fodder in organic farming. Czech $\mathbf{J}$ Genet Plant Breed 50:185-194

Ibrahim MH, Jaafar HZE (2012) Primary, secondary metabolites, $\mathrm{H}_{2} \mathrm{O}_{2}$, malondialdehyde and photosynthetic responses of
Orthosiphon stimaneus Benth. to different irradiance levels. Molecules 17:1159-1176

Irani NG, Hernandez JM, Grotewold E (2003) Regulation of anthocyanin pigmentation. Rec Adv Phytochem 38:59-78

Janoudi A, Poff KL (1990) A common fluence threshold for first positive and second positive phototropism in Arabidopsis thaliana. Plant Physiol 94:1605-1608

Jansen MAK, Hectors K, O’Brien NM, Guisez Y, Potters G (2008) Plant stress and human health: do human consumers benefit from UV-B acclimated crops. Plant Sci 175:445-458

Jansen MAK, Coffey AM, Prinsen E (2012) UV-B induced morphogenesis. Four players or a quartet? Plant Signal Behav 7(9):1185-1187

Joschinski J, Hovestadt T, Krauss J (2015) Coping with shorter days: do phenology shifts constrain aphid fitness? PeerJ 3:e1103. doi:10.7717/peerj.1103

Kaplan I, Halitschke R, Kessler A, Sardanelli S, Denno RF (2008) Constitutive and induced defenses to herbivory in above- and belowground plant tissues. Ecology 89:392-406

Karban R, Agrawal AA (2002) Herbivore offense. Annu Rev Ecol Syst 33:641-664

Khan MAM, Ulrichs C, Mewis I (2010) Influence of water stress on the glucosinolate profile of Brassica oleracea var. italica and the performance of Brevicoryne brassicae and Myzus persicae. Entomol Exp Appl 137:229-236

Khan MAM, Ulrichs C, Mewis I (2011) Water stress alters aphid induced glucosinolate response in Brassica oleracea var. italica differently. Chemoecology 21:235-242

Kirizii DA, Vorobei NA, Kots SY (2007) Relationships between nitrogen fixation and photosynthesis as the main components of the productivity in alfalfa. Fiziol Rast 54:666-671

Kliebenstein DJ (2012) Plant defense compounds: systems approaches to metabolic analysis. Annu Rev Phytopathol 50:155-173

Kordan B, Dancewicz K, Wróblewska A, Gabryś B (2012) Intraspecific variation in alkaloid profile of four lupine species with implications for the pea aphid probing behaviour. Phytochem Lett 5(1):71-77

Lambers H, Chapin FS III, Pons TL (2008) Plant physiological ecology. Springer, New York

Lattanzio V (2013) Phenolic compounds: introduction. In: Ramawat KG, Merillon JM (eds) Natural products. Springer, Berlin, Heidelberg, pp 1543-1580. doi:10.1007/978-3-642-22144-6_57

Legrand A, Barbosa P (2000) Pea aphid (Homoptera: Aphididae) fecundity, rate of increase, and within-plant distribution unaffected by plant morphology. Environ Entomol 29(5):987-993

Lichtenthaler HK, Buschmann C, Doll M, Fietz H, Bach T, Kozel U, Meier D, Rahmsdorf U (1981) Photosynthetic activity, chloroplast ultrastructure, and leaf characteristics of high-light and low-light plants and of sun and shade leaves. Photosynth Res 2:115-141

Liu DD, Chao WM, Turgeon R (2012) Transport of sucrose, not hexose, in the phloem. J Exp Bot 63(11):4315-4320

Ljuština M, Mikić A (2010) A brief review on the early distribution of pea (Pisum sativum L.) in Europe. Ratar Povrt/Field Veg Crop Res 47:457-460

Maguire AJ, Kobe RK (2015) Drought and shade deplete nonstructural carbohydrate reserves in seedlings of five temperate tree species. PLoS ONE 9(2):e85996

Mayoral AM, Tjallingii WF, Castanera P (1996) Probing behaviour of Diuraphis noxia on five cereal species with different hydroxyamic acid levels. Entomol Exp Appl 78:341-348

Mewis I, Khan MAM, Glawischnig E, Schreiner M, Ulrichs C (2012) Water stress and aphid feeding differentially influence metabolite composition in Arabidopsis thaliana (L.). PLoS ONE 7(11):e48661. doi:10.1371/journal.pone.0048661 
Mooney KA, Pratt RT, Singer MS (2012) The tri-trophic interactions hypothesis: interactive effects of host plant quality, diet breadth and natural enemies on herbivores. PLoS ONE 7(4):e34403. doi:10.1371/journal.pone. 0034403

Morant AV, Jørgensen K, Jørgensen Ch, Paquette SM, Sánchez-Pérez R, Møller BL, Bak S (2008) $\beta$-Glucosidases as detonators of plant chemical defense. Phytochemistry 69:1795-1813

Morkunas I, Bednarski W (2008) Fusarium oxysporum induced oxidative stress and antioxidative defenses of yellow lupine embryo axes with different level of sugars. J Plant Physiol 165:262-277

Morkunas I, Marczak Ł, Stachowiak J, Stobiecki M (2005) Sucroseinduced lupine defense against Fusarium oxysporum: sucrosestimulated accumulation of isoflavonoids as a defense response of lupine to Fusarium oxysporum. Plant Physiol Biochem 43:363-373

Morkunas I, Kozłowska M, Ratajczak L, Marczak $Ł$ (2007) Role of sucrose in the development of Fusarium wilt in lupine embryo axes. Physiol Mol Plant Pathol 70:25-37

Morkunas I, Mai VCh, Gabryś B (2011) Phytohormonal signaling in plant responses to aphid feeding. Acta Physiol Plant 33(6):2057-2073

Morkunas I, Woźniak A, Formela M, Mai VC, Marczak Ł, Narożna D, Borowiak-Sobkowiak B, Kühn Ch, Grimm B (2016) Pea aphid infestation induces changes in flavonoids, antioxidative defence, soluble sugars and sugar transporter expression in leaves of pea seedlings. Protoplasma 253(4):1063-1079. doi:10. 1007/s00709-015-0865-7

Nichols EJ, Beckman JM, Hadwiger LA (1980) Glycosidic enzyme activity in pea tissues and pea-Fusarium solani interactions. Plant Physiol 66:199-204

Norin T (2007) Semiochemicals for insect pest management. Pure Appl Chem 79:2129-2136

Pavek PLS (2012) Plant guide for pea (Pisum sativum L.). USDANatural Resources Conservation Service, Pullman

Pentzold S, Zagrobelny M, Rook F, Bak S (2013) How insects overcome two component plant chemical defence: plant bglucosidases as the main target for herbivore adaptation. Biol Rev. doi:10.1111/brv.12066

Pentzold S, Zagrobelny M, Roelsgaard PS, Møller BL, Bak S (2014) The multiple strategies of an insect herbivore to overcome plant cyanogenic glucoside defence. PLoS ONE 9(3):e91337. doi:10. 1371/journal.pone.0091337

Pettersson J, Tjallingii WF, Hardie J (2007) Host plant selection and feeding. In: Harrington R (ed) Van Emden HF. Aphids as crop pests, CAB International, pp 87-114

Philippi J, Schliephake E, Jürgens HU, Jansen G, Orgon F (2015) Feeding behavior of aphids on narrow-leafed lupin (Lupinus angustifolius) genotypes varying in the content of quinolizidine alkaloids. Entomol Exp Appl 156:37-51

Quisenberry SS, Ni X (2007) Feeding injury. In: Van Emden HF, Harrington R (eds) Aphids as crop pests. CAB International, Wallington, pp 331-352

Reese JC, Schwenke JR (1994) Importance and quantification of plant tolerance in crop pest management programs for aphids: greenbug resistance in sorghum. J Agr Entomol 11:255-270

Romanowska E, Wróblewska B, Drożak A, Siedlecka M (2006) High light intensity protects photosynthetic apparatus of pea plants against exposure to lead. Plant Physiol Biochem 44:387-394

Ruban AV (2009) Plants in light. Commun Integr Biol 2:50-55

Ruban AV (2015) Evolution under the sun: optimizing light harvesting in photosynthesis. J Exp Bot 66:7-23

Shao Q, Wang H, Guo H, Zhou A, Huang Y et al (2014) Effects of shade treatments on photosynthetic characteristics, chloroplast ultrastructure, and physiology of Anoectochilus roxburghii. PLoS ONE 9(2):e85996. doi:10.1371/journal.pone.0085996

Soffan A, Aldawood AS (2014) Biology and demographic growth parameters of cowpea aphid (Aphis craccivora) on faba bean (Vicia faba) cultivars. J Insect Sci 14:120

Sorce C, Picciarelli P, Calistri G, Lercari B, Ceccarelli N (2008) The involvement of indole-3-acetic acid in the control of stem elongation in dark- and light-grown pea (Pisum sativum) seedlings. J Plant Physiol 165(5):482-489

Swain T, Hillis WE (1959) The phenolic constituents of Prunus domestica. I.-The quantitative analysis of phenolic constituents. J Sci Food Agric 10:63-68

Sytykiewicz H (2008) Influence of bird cherry-oat aphid feeding on the activity of $\beta$-glucosidase within tissues of its primary host. Aphids Other Hemipterous Insects 14:155-164

Terashima I, Hanba YT, Tazoe Y, Vyas P, Yano S (2006) Irradiance and phenotype: comparative eco-development of sun and shade leaves in relation to photosynthetic $\mathrm{CO}_{2}$ diffusion. $\mathrm{J}$ Exp Bot $57: 343-354$

Tjallingii WF (1985) Electrical nature of recorded signals during stylet penetration by aphids. Entomol Exp Appl 38:177-186

Tjallingii WF (1988) Electrical recording of stylet penetration activities. In: Minks AK, Harrewijn P (eds) Aphids, their biology, natural enemies and control, vol 2B. Elsevier, Amsterdam, pp 95-108

Tjallingii WF (1994) Sieve element acceptance by aphids. Eur J Entomol 91:47-52

Tjallingii WF, Gabrys B (1999) Anomalous stylet punctures of phloem sieve elements by aphids. Entomol Exp Appl 91:97-103

Tjallingii WF, Hogen Esch T (1993) Fine-structure of aphid stylet routes in plant tissues in correlation with EPG signals. Physiol Entomol 18:317-328

Vermerris W, Nicolson R (2008) Phenolic compound biochemistry. Springer, New York

Wang T, Quisenberry SS, Ni X, Tolmay V (2004) Enzymatic chlorophyll degradation in wheat near-isogenic lines elicited by cereal aphid (Homoptera: Aphididae) feeding. J Econ Entomol 97:661-667

War AR, Paulraj MG, Ahmad T, Buhroo AA, Hussain B, Ignacimuthu S, Sharma HC (2012) Mechanisms of plant defense against insect herbivores. Plant Signal Behav 7(10):1306-1320

Wellburn AR (1994) The spectral determination of chlorophylls a and $\mathrm{b}$, as well as total carotenoids, using various solvents with spectrophotometers of different resolution. J Plant Physiol 144:307-313

Weller JL, Foo E, Hecht V, Ridge S, Vander Schoor JK, Reid JB (2015) Ethylene signalling influences light-regulated development in pea. Plant Physiol 169:115-124

Woźniak A, Formela M, Bilman P, Grześkiewicz K, Bednarski W, Marczak $Ł$, Narożna D, Dancewicz K, Mai VC, BorowiakSobkowiak B, Floryszak-Wieczorek J, Gabryś B, Morkunas I (2016) The dynamics of the defense strategy of pea induced by exogenous nitric oxide in response to aphid infestation. Int J Mol Sci 18:329

Wyatt IJ, White P (1977) Simple estimation of intrinsic increase rates for aphids and tetranychid mites. J Appl Ecol 14:757-766

Zarzycki K, Trzcińska-Tacik H, Różański W, Szeląg Z, Wołek J, Korzeniak U (2002) Ecological indicator values of vascular plants of Poland. W. Szafer Institute of Botany Polish Academy of Sciences, Kraków

Zorić L, Krstić D, Ćupina B, Mikić A, Antanasović S, Luković J, Merkulov L (2012) The effect of field pea (Pisum sativum L.) as companion crop on leaf histological parameters of lucerne (Medicago sativa L.). Aust J Crop Sci 6:430-435 